\title{
OS TEMPOS DOS RIOS E DAS CIDADES
}

\author{
Helena Madureira \\ Departamento de Geografia, Universidade do Porto/CEGOT \\ Via Panoramica s/n, 4150-564 Porto, Portugal \\ hmadureira@letras.up.pt
}

\section{Resumo}

A história dos rios pode ser inferida a partir da história das cidades que percorrem. Partindo do reconhecimento da organização territorial da bacia hidrográfica do rio Leça (Portugal) em três momentos temporais das últimas décadas, assinalam-se e contextualizam-se as relações e mútuas adaptações entre rios e cidades, evidenciando-se como os diferentes tempos de decadência e degradação ou revalorização e revitalização entretecem a sua atual condição.

\begin{abstract}
The history of rivers can be inferred from the history of the cities they run through. Based on a systematization of the territorial organization of the Leça river basin (Portugal) in the last decades, we contextualize the relationship and mutual adjustments between rivers and cities, discussing how different times of decay and degradation or revaluation and revitalization interweave its current condition.
\end{abstract}

\section{Palavras - chave}

Cidades, natureza, rios urbanos

\section{Keywords}

Cities, nature, urban rivers 


\section{Introdução: rios, cidades, rios}

A história dos rios transcreve, em grande medida, a história das suas cidades. Os rios impulsionaram a emergência e o desenvolvimento das cidades. Foram fonte primordial de água, recurso escasso sempre valorizado pelas populações para o consumo e a higiene, para o desenvolvimento das atividades agrícolas, artesanais ou industriais, e serviram também como meios de comunicação, de transporte e como facilitadores de práticas comerciais.

A proximidade à água foi tendo, portanto, variadas e por vezes cumulativas vantagens, e as frentes de água constituíram invariavelmente territórios atrativos à fixação das populações. Persistiu assim durante largos momentos da história uma relação de dependência relativa à proximidade e usufruto de cursos água, assente na necessidade de adaptação às suas caraterísticas e de proteção de um recurso essencial à vida e ao desenvolvimento das cidades.

Esta relação de dependência perdeu importância com as amplas transformações derivadas da Revolução Industrial, que alteram drasticamente a relação estrutural e funcional entre as cidades e os seus rios. Na verdade, ainda que a industrialização seja habitualmente associada ao despoletar dos problemas ambientais nas cidades, na realidade os impactes da urbanização sobre os cursos de água sempre se fizeram sentir. De facto, não só os rios condicionaram a génese e desenvolvimento das cidades como foram sempre também afetados e modificados com o desenvolvimento urbano, designadamente pelas descargas domésticas, pelos resíduos das atividades comerciais e manufatureiras ou pela ocupação das margens dos rios. A escala destes impactes era, no entanto, muito menos alargada até à Revolução Industrial. 
As condições ambientais das cidades estão num contínuo estado de transformação, acompanhando as mudanças sociais e económicas das próprias cidades. E, de acordo com MCGRANAHAN et al ${ }^{1}$, os impactes ambientais dos processos de urbanização transformam-se ao longo do tempo quer em tipologia, evoluindo de impactes diretos na saúde para impactes mais abrangentes nos serviços dos ecossistemas, quer em escala temporal, com impactes de período temporal cada vez mais alargado, quer ainda em escala espacial, evoluindo de impactes localizados para escalas cada vez mais abrangentes.

É durante o processo de industrialização, substanciado num conjunto complexo de casualidades recíprocas que envolve transformações económicas, institucionais, infraestruturais, sociais e demográficas, que se dá a transição mais drástica nas condições ambientais nas cidades. Os impactes ambientais são cada vez mais abrangentes, quer em tipologia quer em escala temporal e espacial, alterando drástica e definitivamente a relação entre cidade e ambiente.

Esta fase tumultuosa nas relações entre a cidade e o ambiente, e também com os seus rios, produzse num duplo sentido. Por um lado, ao intenso crescimento da população urbana sem a correspondente melhoria das infraestruturas gerais de saneamento, acresce a forte carga poluente das unidades industriais que se implantavam nas cidades, o que provoca um drástico agravamento das condições de salubridade das cidades e dos seus rios. Por outro lado, a consciencialização da gravidade dos problemas sanitários, sociais e funcionais da cidade industrial, associada a avanços científicos nos campos da microbiologia e na epidemiologia, levaram à consagração de procedimentos de índole higienista que se plasmaram numa mudança radical na relação das cidades com a água. Registam-se progressos técnicos notáveis, com o desenvolvimento de sistemas de abastecimento de água e de drenagem das águas residuais. Mas também, simultaneamente, cresce o fervor das competências técnicas patenteadas na vulgarização da prática de canalização de rios e

${ }^{1}$ MCGRANAHAN, Gordon et al. The Citizens at Risk: From Urban Sanitation to Sustainable Cities. London, Earthscan, 2001. 
ribeiros, que levam ao progressivo afastamento e perda de identidade dos cursos de água em contextos urbanos.

$\mathrm{Na}$ atualidade, os rios e as frentes ribeirinhas urbanos são aclamados como elementos centrais de composição urbana, de promoção da qualidade de vida urbana e, em termos gerais, da sustentabilidade ambiental. Esta reivindicação dos rios e frentes ribeirinhas responde, obviamente, a uma fase conjuntural de mutuas adaptações, compondo um dos ciclos que podemos analiticamente sistematizar na longa história entre a cidade e a água.

\section{Os tempos cíclicos das relações entre as cidades e os seus rios}

Vários autores têm vindo a sistematizar as relações e as mútuas adaptações entre cidades e rios evidenciando, no essencial, que a relação cidade-rio foi ao longo da história marcada por mudanças cíclicas, entre decadência e degradação por um lado, e revalorização e revitalização por outro ${ }^{2}$.

De facto, os rios abraçaram ao longo da história diferentes funções sociais e significados culturais, sendo identificáveis, nas palavras de MAUCH e ZELLER ${ }^{3}$, as fases de temor e controlo, submissão individual e exuberância profissional enquanto marcas distintivas da história partilhada entre rios e cidades.

Ainda no registo da sistematização, SARAIVA ${ }^{4}{ }^{5}$ organizou a evolução dos paradigmas subjacentes às relações entre o homem e a natureza, e também entre as cidades e os rios, em cinco

${ }^{2}$ BAPTISTA, Marcio; CARDOSO, Adriana. "Rios e cidades: uma longa e sinuosa história..." In Rev. UFMG. Belo Horizonte, 2013, v. 20, n. 2, p. 124-153.

${ }^{3}$ MAUCH, Christof; ZELLER, Thomas. "Rivers in History: Designing and Conceiving Waterways in Europe and North America" In German Historical Institute Bulletin. Washington DC, 2004, n. 34, p. 220-227.

${ }^{4}$ SARAIVA, Maria da Graça. O rio como paisagem: Gestão de corredores fluviais no quadro do ordenamento do território. Lisboa, Fundação Calouste Gulbenkian e Fundação para a Ciência e a Tecnologia, 1999. 
principais fases: i) temor e sacralização, correspondendo a um contexto em que os rios são respeitados pelo seu carácter mítico e simbólico, como fonte essencial de vida, mas simultaneamente como fonte de temor, de receio, em face dos riscos de cheias e inundações que incorporam; ii) harmonia e ajustamento, quando persiste uma relação de mútua convivência, em que sociedade conhece e respeita os ciclos, benefícios e contingências naturais associadas aos cursos de água, desenvolvendo formas de adaptação e ajustamento harmoniosas que não provocam grandes alterações nos sistemas naturais; iii) controlo ou domínio, traduzida na persecução do domínio sobre os recursos e os seus ciclos, numa tentativa de maximizar o aproveitamento dos benefícios e de minimizar os seus malefícios, sendo prática corrente a modificação intensa dos sistemas fluviais, através de obras de regularização para controlo de eventos extremos; iv) degradação e sujeição, em que o controlo e domínio intensivos dos cursos de água, levaram à artificialização dos sistemas fluviais, à modificação do seu regime e dinâmica, ao comprometimento das componentes dos seus ecossistemas e, sintomaticamente, à sua transformação em elementos indesejados pela sociedade, sendo frequentemente 'escondidos' da paisagem urbana; v) recuperação e sustentabilidade, correspondendo à consciencialização do valor ambiental, ecológico, cultural, social, económico e simbólico dos rios e áreas ribeirinhas, e a novas atitudes e projetos tendo em vista a valorização dos rios e paisagens ribeirinhas nas cidades.

TVEDT e OESTIGAARD ${ }^{6}$ apresentam uma proposta de leitura e interpretação das relações a cidade e a água simultaneamente anacrónica e sincrónica. Consideram que, seja qual for a cidade, a compreensão das relações entre a cidade e a água deve ter em conta o sistema da água na sua multifuncionalidade e especificamente a análise de três camadas analíticas interconectadas. A primeira camada corresponde aos aspetos físicos, designadamente à forma e ao comportamento dos

${ }^{5}$ SARAIVA, Maria da Graça. Cidades e rios: perspectivas para uma relação sustentável. Lisboa, Parque Expo, 2010.

${ }^{6}$ TVEDT, Terje; OESTIGAARD, Terje. “Urban Water Systems: A Conceptual Framework” In: TVEDT, T; OESTIGAARD, T (Orgs.). History of Water. London, I.B. Tauris, 2014, p. 1-25. 
cursos de água. Tal inclui por exemplo a precipitação, a evaporação, o regime hídrico e os padrões de desenvolvimento que podem originar. A segunda camada analítica compreende as alterações e adaptações à 'paisagem física da água', fruto da sua apropriação ao longo da história de acordo com variadas motivações e para diversos fins. Tal envolve a apreensão do modo como a população e a cidade de têm apropriado da água e dos cursos de água como recurso mobilizável para o seu desenvolvimento. A terceira e última camada corresponde às ideias e conceções culturais sobre a água, incluindo a compreensão dos procedimentos em termos de gestão dos cursos de água, e como esses procedimentos e conceções têm sido influenciados ao longo do tempo pelo contexto físico (primeira camada analítica) e pelo contexto histórico de controlo da água (segunda camada analítica) em cada cidade.

A relação entre os rios e as suas cidades parece, portanto, obedecer a um ritmo que ainda que em diferentes temporalidades se exprime indiferenciadamente pelos territórios urbanos. Importa, no entanto, conhecer os contextos territoriais e temporais específicos em que as cidades e os seus rios se entretecem nesta complexa e dinâmica teia de relações.

\section{O rio Leça: o rio que estrutura, que se esconde, e que se redescobre na região metropolitana do Porto}

Neste trabalho utilizamos o rio Leça e a sua bacia hidrográfica como mote para a exploração da evolução das relações entre a cidade e os rios (Figura 1). O rio Leça nasce em Monte Córdova, no concelho de Santo Tirso, e no seu percurso de cerca de $45 \mathrm{Km}$ atravessa a coroa norte da região metropolitana do Porto (Portugal). Lemos os processos de transformação da paisagem da Bacia do 
Leça ao longo da segunda metade do século através de três diagramas síntese (Figura 2) que esquematizam a sua organização territorial em três momentos temporais: décadas de 50,80 e $2000{ }^{7}$

Centramo-nos, portanto, não no Douro, curso de água que moldou a emergência e o crescimento da cidade do Porto, mas no Leça, rio que testemunhou e acompanhou a estruturação da cidade numa escala metropolitana. Temos aqui, portanto, a oportunidade de pensar a relação entre cidade e rio num contexto de urbanização mais recente, mas muito mais veloz. Desde a nascente até à Foz, um estuário de pequenas dimensões ocupado na sua quase totalidade pelo porto de Leixões, o Rio Leça percorre contextos bem diferenciados a nível de inserção nas dinâmicas territoriais da região metropolitana do Porto, desde os menos urbanizados na área mais a montante da bacia até aqueles mais urbanizados no sector jusante da bacia. Obtemos um retrato a dois tempos, que evidencia simultaneamente o decurso dos processos de urbanização emanados essencialmente do Porto centro da cidade região, e a persistência de formas de organização territorial ancestrais.

\footnotetext{
${ }^{7}$ Retomamos aqui, com um maior desenvolvimento e com uma nova perspetiva de abordagem, os diagramas síntese publicados em MADUREIRA, Helena. A Infraestrutura verde da bacia do Leça: uma estratégia para o desenvolvimento sustentável na Região Metropolitana do Porto. Porto, Edições Afrontamento,
} 2011. 


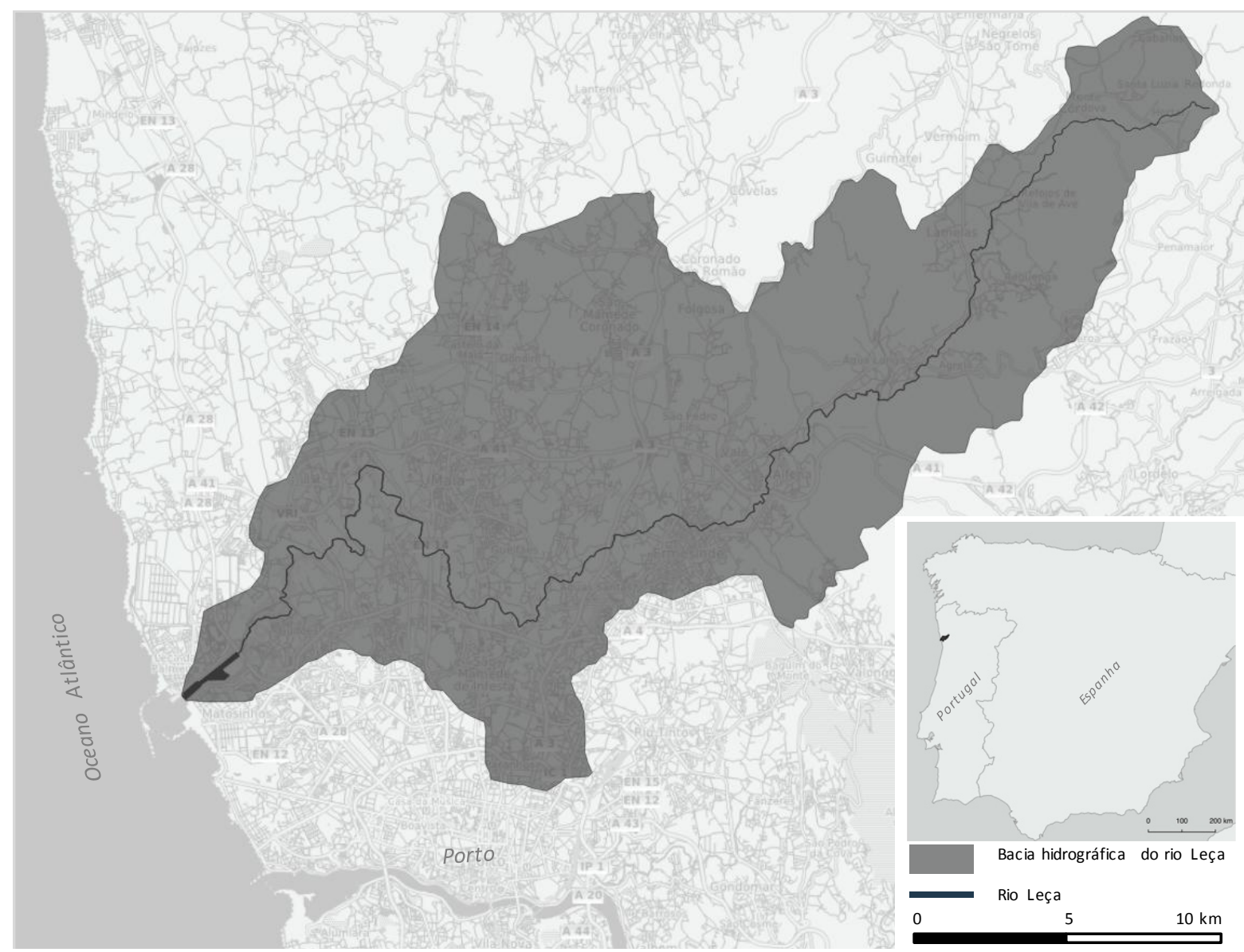

Figura 1 - O Rio Leça e a sua bacia

Estes diagramas servem-nos, pois, de base a uma reflexão sobre a perda de identidade da bacia hidrográfica enquanto unidade territorial, ou, de outra forma, sobre o progressivo distanciamento e alheamento relativamente ao rio enquanto elemento fundamental e estruturante dessa unidade. São aí visíveis as grandes tendências de transformação, nesta hoje consolidada coroa norte da região metropolitana do Porto, ao longo das últimas décadas: a progressiva expansão e descentralização da mancha urbana, o forte desenvolvimento das acessibilidades, as alterações no padrão locativo da 
indústria a retração das áreas agrícolas e a concentração espacial das áreas florestadas ${ }^{8}$. E, como veremos, e como corolário, o negligenciamento do Rio Leça.

Os relatos de inícios do século apresentavam o Leça como um rio bucólico, calmo, ponteado de moinhos e azenhas, correndo por entre bouças, milheirais e humedecendo férteis várzeas ${ }^{9}{ }^{10}$. Esse seria genericamente o seu retrato na década de 50, altura em que à imagem da generalidade do país, a bacia do Leça apresentava ainda um quadro profundamente rural. Destacavam-se apenas dois núcleos urbanos, Matosinhos na foz do rio, e Paranhos, refletindo a expansão da mancha urbana a partir do centro nevrálgico do Porto. E aí, nesses contextos mais urbanizados, seriam plenamente identificáveis as tendências de controlo dos cursos de água, designadamente pela persecução das ideias e práticas higienistas que dominaram as cidades europeias durante séculos. Ainda como exemplo paradigmático da fase de controle da cidade sobre os seus rios, retenhamos a construção porto comercial marítimo de Leixões, na foz do Leça, que tendo alterado profundamente a relação morfológica e funcional do aglomerado populacional com o rio, constituiu o elemento primordial no processo de consolidação urbana de Matosinhos.

Para lá destes núcleos urbanos, a Bacia do Leça era dominada por uma estrutura de povoamento rural genericamente dispersa associada a um sistema campo-bouça. A manutenção deste quadro dependia, portanto, de uma estreita relação com os recursos naturais, e especialmente com a água.

Podemos assim considerar que estaríamos, em grande parte do território abrangido pela bacia do Leça, numa fase de harmonia na relação entre a sociedade e o rio, e este representaria um elemento identificador do território, como a toponímia de alguns locais ainda ilustra (Leça da Palmeira, Leça do Balio, Águas Santas, Água Longa, etc.). Ao longo das suas margens estendiam-se construções

\footnotetext{
8 MADUREIRA, Helena. A Infraestrutura verde da bacia do Leça: uma estratégia para o desenvolvimento sustentável na Região Metropolitana do Porto. Porto, Edições Afrontamento, 2011

${ }^{9}$ NOBRE, Augusto. Leça da Palmeira. Recordações e estudos de há sessenta anos. Porto, E.A, 1945. ${ }^{10}$ MORAIS, Cunha, A Arte e a Natureza em Portugal. Porto, Emílio Biel \& Ca 1908.

Dossiê HISTÓRIA URBANA ISSN 2238-9288 - 35 -
}


rurais, com predominância para os seus moinhos, as suas pontes, e as suas noras. Percorrendo a envolvente norte do centro urbano do Porto, o rio Leça afigurava-se, em suma, como um importante recurso para a fixação da atividade agrícola que abastecia o centro urbano de hortícolas e frutícolas.

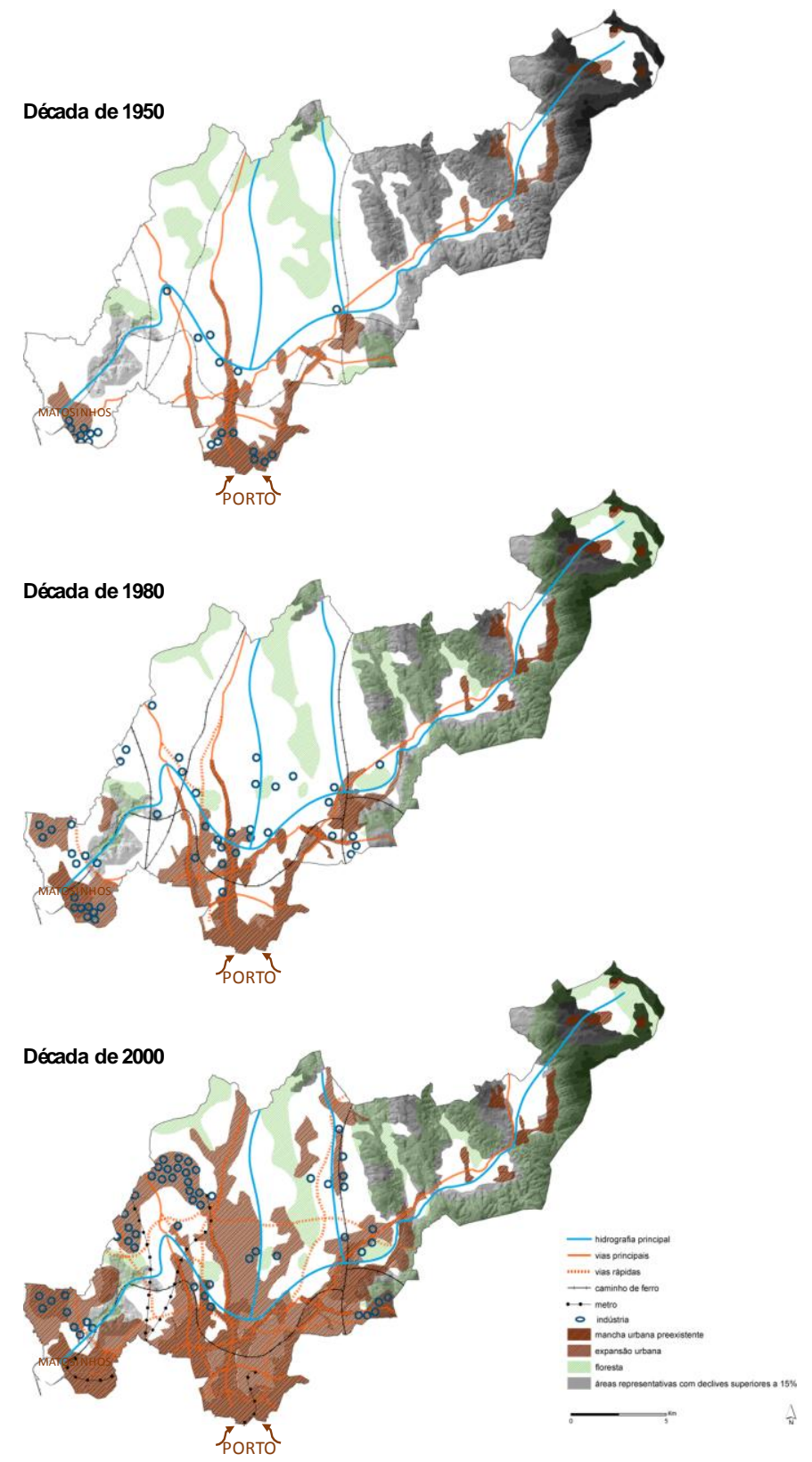

Figura 2 - Diagramas síntese da evolução da organização territorial da Bacia do Leça. Elaborados com base nas Cartas Militares do Instituto Geográfico do Exército na escala 1:25.000 
Os anos 50 foram um importante marco na história contemporânea portuguesa, na medida em que representaram o arranque definitivo, embora retardado, da modernização da economia, baseada sobretudo no desenvolvimento de sectores da indústria pesada característicos da 2a Revolução Industrial, que ainda não existiam no país. Também para o Porto aquela década foi importante, não tanto talvez devido ao investimento produtivo, mas sobretudo devido aos investimentos em infraestruturas físicas que foram lançados nessa década ou de algum modo entraram então em pleno funcionamento ${ }^{11}$.

A década de 50 marca assim um início de profundas alterações na organização territorial da Bacia do Leça, que se acentuarão nas décadas seguintes, e que terão como um dos corolários a transformação relação com o rio.

Em primeiro lugar, assiste-se a uma progressiva perda de importância da atividade agrícola enquanto atividade económica. E este facto representa, por si só, um primeiro fator de distanciamento da sociedade relativamente ao rio e às suas margens férteis. Paralelamente, a indústria marca uma crescente presença na bacia do Leça e, sobretudo numa fase inicial, implantase junto ao rio e seus principais afluentes. No diagrama representativo da organização territorial da bacia do Leça nos anos 80 (Figura 2) podemos verificar a coincidência espacial da implantação das unidades industriais com a proximidade aos principais cursos de água.

Estaríamos aqui, do ponto de vista da relação entre a sociedade e os rios, e voltando à esquematização proposta por SARAIVA ${ }^{12}{ }^{13}$, nas fases de controlo e degradação. E à medida que se acentua o carácter industrial das margens ribeirinhas, inicia-se, na nossa perspetiva, a fase mais crítica relativamente à identificação da sociedade com o rio Leça. De facto, ao acentuar a degradação ambiental e paisagística dos cursos de água e das suas margens, acentua a degradação das áreas agrícolas remanescentes e torna-o num território pouco atrativo à população. $\mathrm{O}$ crescimento da mancha urbana reflete de facto, quer na escala da bacia quer na escala dos aglomerados urbanos, uma desvalorização do rio enquanto recurso, revelando antes um alheamento relativamente à sua presença no território.

${ }^{11}$ CARDOSO, Abílio. Do desenvolvimento do planeamento ao planeamento do desenvolvimento. Porto, Edições Afrontamento, 1996.

${ }^{12}$ SARAIVA, Maria da Graça. O rio como paisagem: Gestão de corredores fluviais no quadro do ordenamento do território. Lisboa, Fundação Calouste Gulbenkian e Fundação para a Ciência e a Tecnologia, 1999.

${ }^{13}$ SARAIVA, Maria da Graça. Cidades e rios: perspectivas para uma relação sustentável. Lisboa, Parque Expo, 2010. 
O diagrama representativo da organização territorial da bacia do Leça no início do século XXI sintetiza esta fase crítica relativamente à identificação da sociedade com o rio Leça. A indústria já não tem como padrão locativo preferencial as margens ribeirinhas, que testemunham agora, com algumas exceções, o abandono das antigas unidades industriais. Por outro lado, a mancha urbana ultrapassou o rio, em toda a área jusante da bacia, sem que com ele tenha estabelecido uma relação de complementaridade espacial e funcional.

Lenta e progressivamente esta fase de alheamento socio-territorial tem vindo a dar lugar a uma redescoberta do rio Leça, marcada pela consciencialização simultânea e não articulada entre os vários agentes territoriais dos valores ambientais, ecológicos, económicos, sociais, culturais e simbólicos do rio. Multiplicam-se iniciativas, na maior parte dos casos desarticuladamente, para resolver a ainda premente despoluição da água e intervenções pontuais para a requalificação das margens do rio, revelando a complexidade da atual fase de redescoberta da água na cidade.

\section{Conclusão: o tempo de redescoberta da água na cidade}

Os rios urbanos têm vindo a ser 'redescobertos' num movimento que congrega as esferas políticas e científicas, e também o crescente interesse dos cidadãos, levando à multiplicação de projetos para o restauro e a requalificação dos cursos de água urbanos

Várias circunstâncias concorrem para explicar este movimento. Em primeiro lugar, acompanha a crescente sensibilização para as problemáticas ambientais e a gradual consciencialização da importância das cidades na promoção da sustentabilidade ambiental. Em segundo lugar, este movimento responde à tendência generalizada de alteração dos usos do solo junto dos cursos de água, sendo que o abandono de antigas áreas industriais, que agora seguem outros padrões locativos, é visto como uma oportunidade para inserir elementos amenizadores do contexto urbano. Por último, este amplo interesse pelo restauro e a requalificação dos rios urbanos encontra também explicação na oportunidade de se potenciarem as atividades recreativas, cada vez mais valorizadas pelas populações, e de qualificar esteticamente a paisagem urbana.

Após longas décadas de abandono que imprimiram profundas e por vezes inultrapassáveis marcas territoriais, os rios urbanos são crescentemente vistos como espaços de oportunidade ambiental, económica, social, recreativa, cultural e identitária. Sobrepõem-se perspetivas de requalificação tendencialmente dicotómicas, umas enraizadas numa tradição puramente ambiental e ecológica que 
privilegia a qualidade da água e a restituição das continuidades ecológicas das margens esquecendo o seu contexto urbano, outras enraizadas numa tradição urbanística que impõe continuidades no tecido urbano esquecendo as primordiais funções ambientais e ecológicas dos rios e suas margens ${ }^{14}$. Importa pois, que a redescoberta dos rios na cidade se enraíze num modo de olhar e intervir na cidade que expresse a sua materialidade não só como como elementos naturais ímpares, não só como elementos assimilados pelos processos de urbanização, não só como reservatório de sociabilidades, memória coletiva e de identidade, mas sobretudo como elementos de oportunidade para a interconexão de todas estas potencialidades.

${ }^{14}$ JUNKER, Berit; BUCHECKER, Matthias. "Aesthetic preferences versus ecological objectives in river restorations" In Landscape and Urban Planning. Springer, 2008, v. 85, n. 3-4, p. 141-154. GOBSTER, Paul et al. "The shared landscape: what does aesthetics have to do with ecology?" In Landscape Ecology. Springer, 2007, v. 22, n. 7, p. 959-972. 